\title{
A Celebration of History, Scientific Progress, and Pioneers Who Revolutionized Materials Science
}

\section{Jonathan D. Madison}




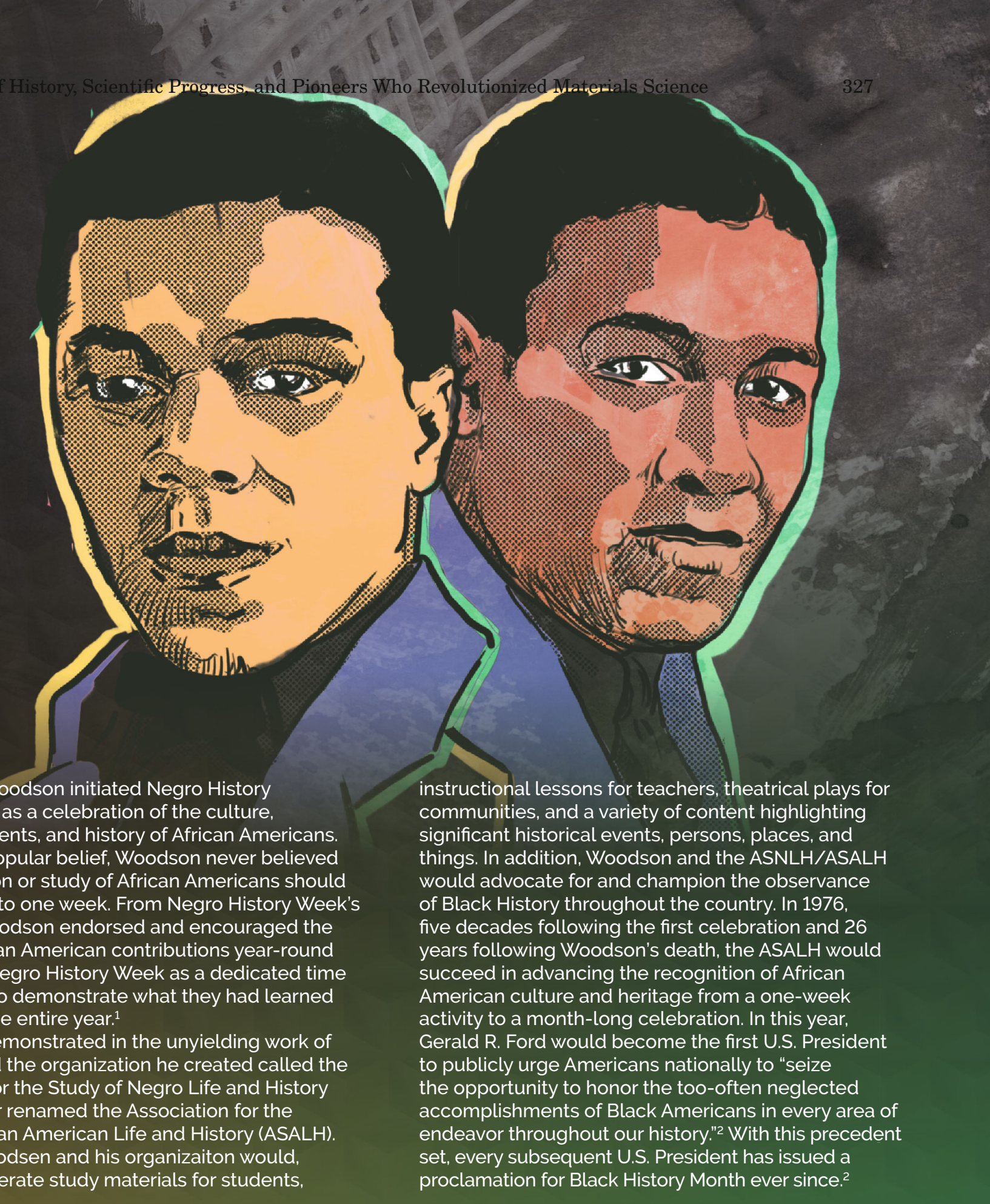

Carter G. Woodson initiated Negro History Week in 1926 as a celebration of the culture, accomplishments, and history of African Americans. Contrary to popular belief, Woodson never believed the recognition or study of African Americans should be relegated to one week. From Negro History Week's inception, Woodson endorsed and encouraged the study of African American contributions year-round and viewed Negro History Week as a dedicated time for students to demonstrate what they had learned throughout the entire year. ${ }^{1}$

This was demonstrated in the unyielding work of Woodson and the organization he created called the Association for the Study of Negro Life and History (ASNLH), later renamed the Association for the Study of African American Life and History (ASALH). Together, Woodsen and his organizaiton would, for years, generate study materials for students,

instructional lessons for teachers, theatrical plays for communities, and a variety of content highlighting significant historical events, persons, places, and things. In addition, Woodson and the ASNLH/ASALH would advocate for and champion the observance of Black History throughout the country. In 1976, five decades following the first celebration and 26 years following Woodson's death, the ASALH would succeed in advancing the recognition of African American culture and heritage from a one-week activity to a month-long celebration. In this year, Gerald R. Ford would become the first U.S. President to publicly urge Americans nationally to "seize the opportunity to honor the too-often neglected accomplishments of Black Americans in every area of endeavor throughout our history." With this precedent proclamation for Black History Month ever since.?

\section{CELEBRATE ALL MONTH LONG}

Watch TMS social media during Black History Month to continue the celebration of both the historic pioneers featured in this issue of JOM: The Magazine, and those who are making history today. 
This February, TMS embraces the spirit and intent of the prolific academic, Carter G. Woodson, and celebrates the existence of both historic and modern contributors to the field of materials and materials processing who are both brilliant scientifically and African or African American ethnically. All month, modern trailblazers in the field will be highlighted on TMS' social media channels. Conversely, within this issue of JOM: The Magazine, four historic pioneers in the field are highlighted through three articles for their revolutionary scientific contributions.

The first article in this series highlights a celebrated, modern-day pioneer in crystallography and diffraction techniques whose body of work significantly contributed to our understanding of graphite. He would also develop techniques necessary to reveal light elements previously thought to be transparent to $x$-rays. Among other accolades and appointments, he would serve as a researcher at Lawrence Berkeley National Laboratory and chair for the Materials Department at the University of California, Berkeley.

The second article explores the amazing achievements of two brothers who at the turn of the 20th century would acquire bachelor's, master's, and doctoral degrees from some of the most elite American universities. They would each go on to teach at several Historically Black Colleges and Universities (HBCUs) and then make impressive research impacts to help unlock the secrets of atomic energy in the Manhattan Project. One would even serve as the first and only African American supervisor for an all-white corrosion group supporting the war effort at Columbia University.

The third article features the life and legacy of the first African American woman to be employed by the Dow Chemical Company in a scientific R\&D position. She would would build an impressive, life-long career as a particle scientist and polymer chemist. Her discoveries would dramatically impact the pharmaceutical, catalyst, cosmetic, and latex paint industries for generations. Her persistence through trial and adversity are a keen reminder of the challenges and discrimination faced by many African Americans who came before her and many who have followed.

My fellow authors and I hope that these portraits in excellence will serve to highlight just a few of the fantastic achievements made by African Americans in the field. For all people of color who undertake a career in science: while our ethnicity may, in some arenas, categorize us, like all other scientists, it is our intellectual and scientific achievements that define us. Happy Black History Month.
"A Celebration of History, Scientific Progress, and Pioneers Who Revolutionized Materials Science," serves as an introduction to a thematic group of articles in the February 2022 issue of JOM: The Magazine, recognizing the contributions of several African American materials scientists. This special Black History Month article package is a feature series developed by the TMS Diversity, Equity, and Inclusion Committee. For additional information, contact Kaitlin Calva, JOM: The Magazine Managing Editor, at kcalva@tms.org.

"For all people of color who undertake a career in science: while our ethnicity may, in some arenas, categorize us, tike all other scientists, it is our intellectual and scientific achievements that define us."

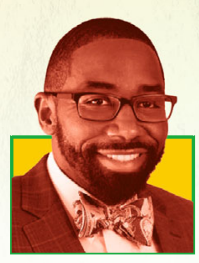

Jonathan D. Madison is program director in the Division of Materials Research at the National Science Foundation. A TMS member since 2003, Madison chaired the organizing committee for the third Summit on Diversity in the Minerals, Metals, and Materials Professions. He is currently the chair of the DEI Committee's Race \& Ethnicity Working Group.

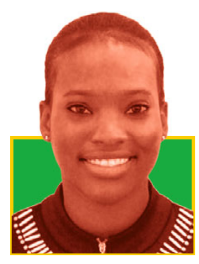

Editor's Note: JOM: The Magazine would also like to thank Tashiema $L$. Ulrich, R\&D associate staff, Los Alamos National Laboratory, for her work as curator on this Black History Month article series. A TMS member since 2020 , Ulrich is the JOM co-liaison for the Diversity, Equity, and Inclusion Committee.

\section{References}

1. "Feb. 7, 1926: Carter G. Woodson Launched Negro History Week" (Zinn Education Project, 2021), https://wwww.zinnedproject.org/news/tdih/ carter-woodson-black-history-month/. Accessed 2 November 2021.

2. "African American History Month" (The Library of Congress), https://africanamericanhistorymonth. gov/about/. Accessed 2 November 2021. 